\title{
Energy efficient smart street light for smart city using sensors and controller
}

\author{
Aziera Abdullah, Siti Hajar Yusoff, Syasya Azra Zaini, Nur Shahida Midi, Sarah Yasmin Mohamad \\ Department of Electrical and Computer Engineering, International Islamic University Malaysia (IIUM), Malaysia
}

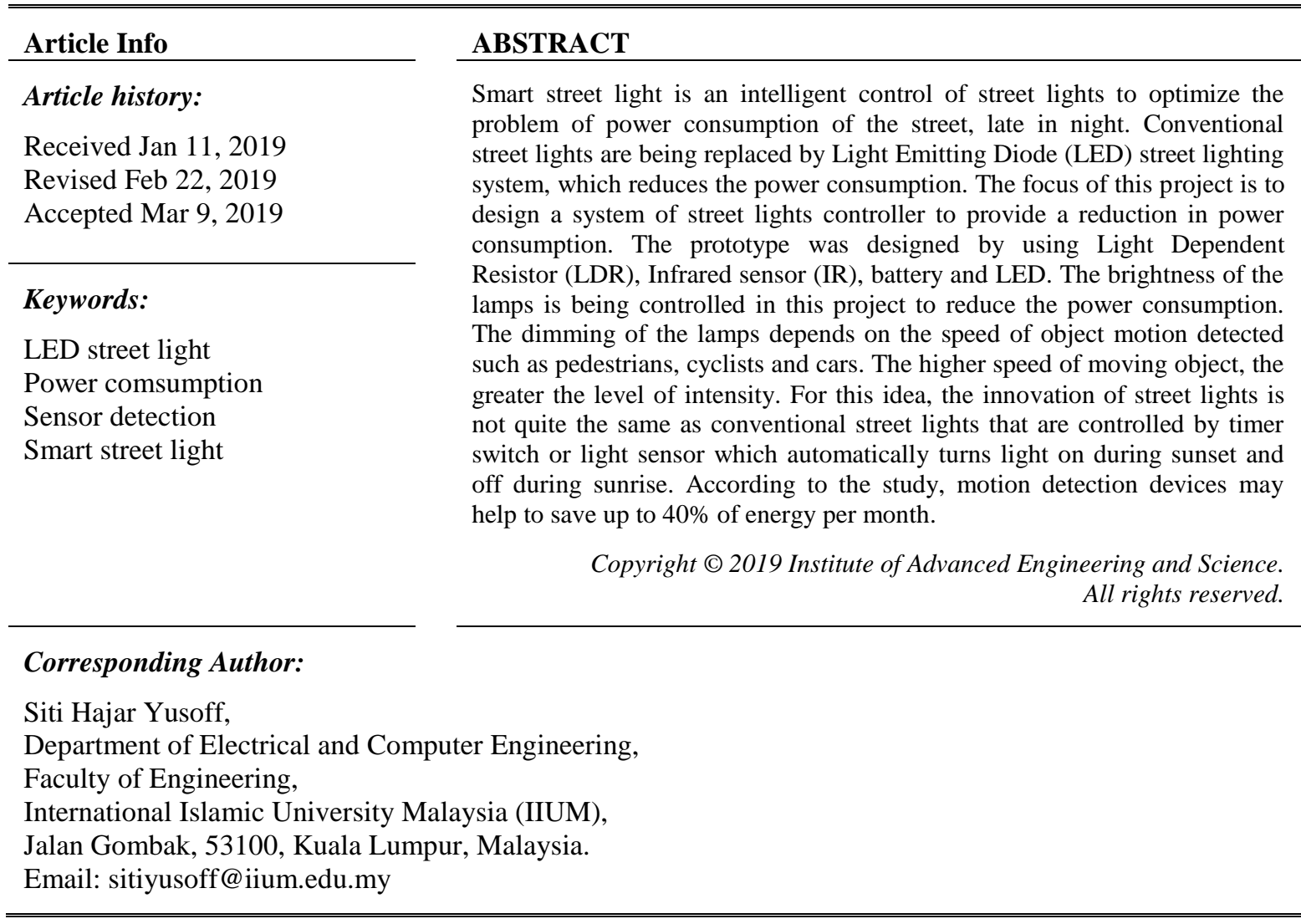

\section{INTRODUCTION}

As technology advances day by day, it is priority matter to develop an exclusive smart street light to reduce energy consumption and increase road safety. Based on The Europe 2020 Strategy characterizes three focuses for atmosphere change and vitality, such as $20 \%$ diminishment of nursery gas emanation, 20\% expansion in vitality generation from sustainable sources, and no less than $20 \%$ expansion of the energy efficiency.

Road lighting qualities about $19 \%$ of the overall utilization of electrical energy and involves $6 \%$ of worldwide emanations of nursery gasses. A diminishing of $40 \%$ of energy spent for lighting intentions is proportional to take out a half of the emanations from the creation of power and warmth age in the US. In this unique circumstance, open road lightning; which is a basic group benefit plays an imperative part as it impacts for around $40 \%$ on the urban communities' energy budget. Therefore, in readiness of the EU responsibilities, tramlining the lighting administration is an essential target for the regions. The current street lights now were replaced by LED street lighting systems which reduces the use of electricity. The characteristics of LED is that the intensity can be controlled easily. Despite that, the light turns on when: dark and turn off when bright automatically. It is such huge waste of power consumption when the street light in "on" condition when the road is empty. From an article of Smart street lights (2013), Proceedings-2013 Texas Instruments India Educators' stated that energy consumed by existing system is high and is not achieving maximum productivity. This can be explained by 2 points here, inc. 
a. The current system used has a timer for the light to turn on and off at dark or bright which is not that suitable as the weather is unpredictable. Sometimes it may get dark earlier than the set time especially during rainy day and get bright earlier than usual day.

b. When the pedestrian or any objects move slowly, the power consumption used it just a waste.

In conjunction with high technology development nowadays, the concept of Smart City is one of the main future targets for a better environment. The UK Department for Business, Innovation and Skills (BIS) considers smart cities a process rather than static outcome, in which increased citizen engagement, social capital and digital technologies make cities more livable and better able to respond to challenges. Smart city concept is depending on two phenomena which are the urbanization problems and the development of recent technologies [1]. The issue of waste management should be given more attention especially when it comes to power consumption. Conventional street lighting systems use constant illumination lighting which leads to high energy consumption up to $60 \%$ of total electricity expenditure [2]. Furthermore, forecasts show that the energy spending for street lights is likely to increase over the next few years as the demand and price for electricity increase. Many urban areas are currently facing high carbon emission due to public lighting, which are contributor to climate change. For instance, in Harrow, street lighting consumes 6,551,500 kWh of electricity, which is lead to emissions of around 3900 tons of carbon manually.

Recently, street lighting policy requires all lights to be operational during the whole night, because of security reasons. This bring to the inefficient energy management such as shorter lamps' life and causes light pollution [3]. Considering the problems of street lighting methods, it has brought out the idea to improve the street lights behavior system so that it is environmentally friendly and cost effective.

A perfectly designed, energy efficient street light controller has to allow people travelling at night with better condition and reduce energy usage and electricity cost. This also should enhance the presence of surrounding. Up till today, the current lighting system is outdated in term of the design and defectively sustained. Hence, it consumes the enormous amounts of energy. The broadest explanations behind wasteful road lighting frameworks in cities are [2]:

a. Poor design

b. High power consumption

c. Inefficient system

One of the alternatives ways to reduce the power consumption in street lights are by replacing metal halide lights to Light Emitting Diode (LED). However, replacing this halide lights to LED is still insufficient enough to reduce the power consumption considerably. Thus, a new smart street light is introduced to tackle this problem. A few countries such as India, US, and Canada have shown their interest in smart street light system. Smart street lights system includes street light management, energy conservation and maintenance purpose [4]. The proposed design of smart lighting structure is discussed in this paper where the main aim is to reduce the cost of power consumption.

This paper is organized as follows: Section II presents the smart street lights solution which includes LED lamps, controlled sensors and object movement that affect light intensity. In Section III, the proposed system of smart street lights which consists of system flowchart and the design of prototype is presented. Results and analysis have been shown in Section IV. The paper concludes in Section V.

\section{SMART STREET LIGHTS SOLUTION}

There are three main components in a smart street light. These are LED lamps, controlled sensors and object movement.

\subsection{LED lamps}

One of the quick solutions has been made by the Malaysian authority where all the streets light need to change to LED lamps in order to reduce energy consumption [5]. This replacement is replacing all the consuming High-Pressure Sodium lamps or Metal Halide (400 W) with low power consuming LED lamps $(<150 \mathrm{~W})$. This LED lamps enhances the lighting system by providing better luminance, better visibility and current rendering capability [4-5].

\subsection{Controlled sensors}

As shown in Figure 1 is the concept of smart street light in a city. The system is using controlled sensors to detect pedestrians or vehicles for the light to turn on during night time [6]. If a person crosses the street starting at position A, sensor will detect the movement and turn on the light at lamp post 1 and 2 for instance. When the pedestrian continues to walk until position E, sensor at lamp post number 3 and 5 will then detects movements and automatically light at these posts will turn on and the lamp post 1 and 2 will turn 
off [6]. This will reduce the energy consumption instead of all the street lights are turn on during whole night [7].

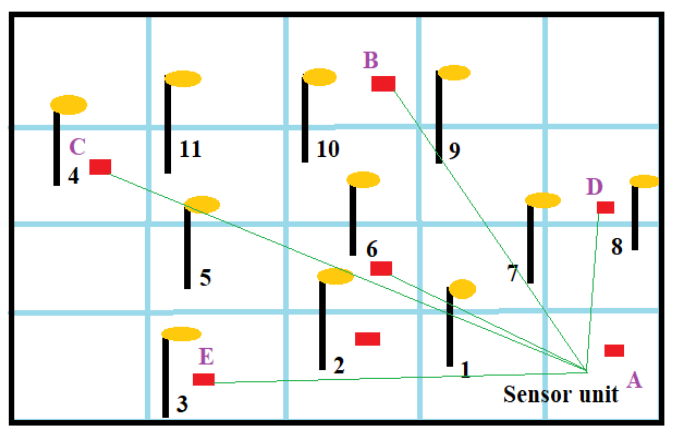

Figure 1. The components for the smart street light [8]

\subsection{Object movement}

Object movement can be classified in three speed categories. Firstly, in low mode which is pedestrians with the range of speed between $0-5 \mathrm{~km} / \mathrm{h}$ while second is medium mode indicates cyclists with the range between $7-15 \mathrm{~km} / \mathrm{h}$ and lastly is high mode for cars with the range of speed more than $16 \mathrm{~km} / \mathrm{hr}$. Figure 2 shows two different situation and the different of light intensity respect to the speed of moving object. In situation A, when the sensor detects a car with a speed of $30 \mathrm{~km} / \mathrm{h}$, the lightning level increases to $80 \%$ while in situation $\mathrm{B}$, the lighting level decrease to $20 \%$ when sensor detects slow moving object. If there is no movement is detected, the luminaries work at a lighting level of 20\% [9].

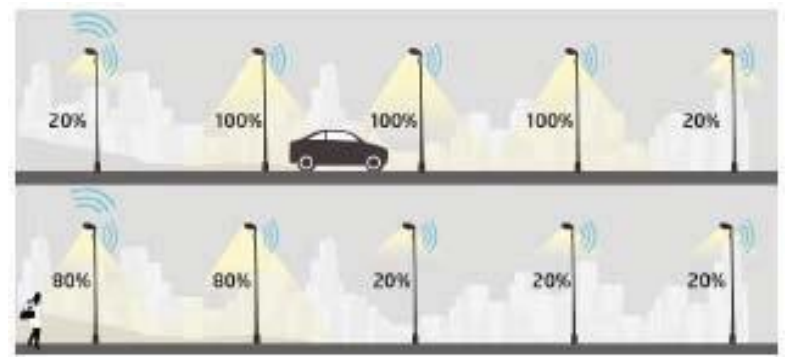

Figure 2. Different setting for different object [9]

\section{RESEARCH METHOD}

This paper proposed a street light that will turn on at night but with different light intensity depending on the road users. The Light Dependent Resistor (LDR) will act as sensor that can adjust the light intensity for different situation. If less than $80 \%$ of sunlight is detect, light will turn on [9]. Figure 3 shows the main idea of this project. The street light will be turned on during night as safety of surrounding but the intensity of light is low. The LDR will act as a sensor for this situation. If less than $70 \%$ of sunlight is detected, light will turn on. There are two IR sensors which are indicated as sensor 1 and sensor 2 are used to detect the speed of movement object. In this project, the speed of the object is only classified by bicycle (cyclist), pedestrian and car. When the object approaches the Sensor 1, it will start to calculate the time taken to reach at Sensor 2. Sensor 2 will stop the time taken when the object reaches Sensor 2 [10]. To obtain the speed of the object, the value of distance is divided by the time taken. Figure 3 shows the circuit diagram of proposed project which include Arduino Uno, battery and LED. The listed components are shown in Table 1.

In Figure 4, the overall of the system has been showed. Arduino Uno will have two ways of communication with street light. A 9V battery is used to support the voltage from the Arduino. Two types of sensors are used in this project which is LDR to detect the darkness of surrounding and IR sensor to detect the speed of object. 


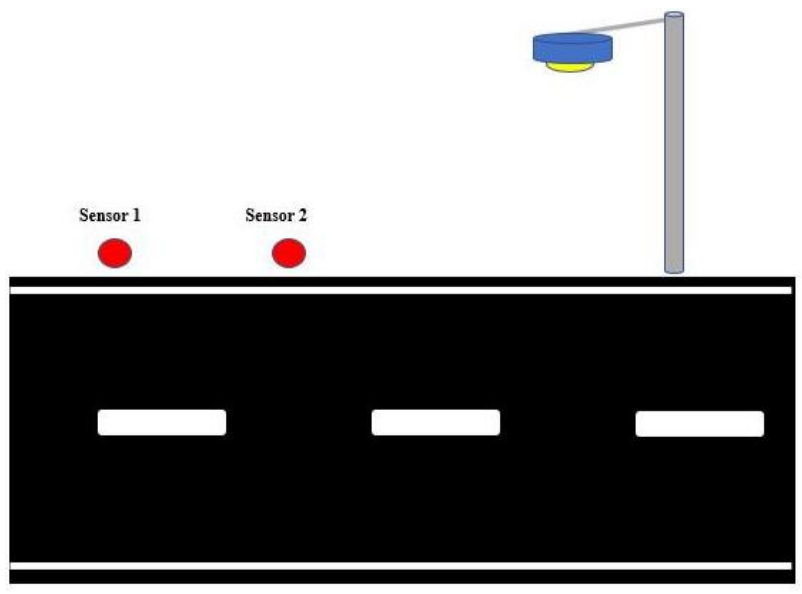

Figure 3. Ideas of smart street light

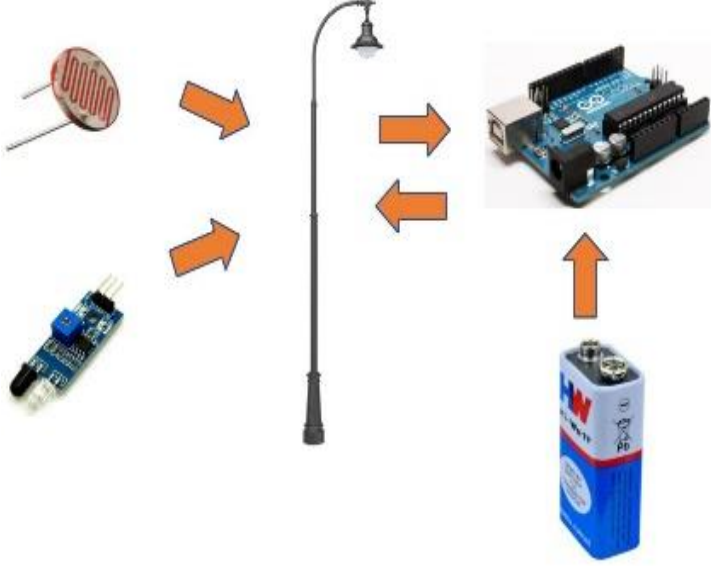

Figure 4. Overall project proposed diagram

Based on Table 1, the most important component is LDR sensor to detect the darkness. While to detect the object movement IR sensor is used. Arduino UNO is software to run the programming. To support the high voltage of LED, 9V battery are connected to the Arduino. Table 1 shows the details of components used in this project.

Table 1. Description of components

\begin{tabular}{|c|c|c|c|}
\hline No. item & Name & Description & Component \\
\hline 1. & $\begin{array}{l}\text { Arduino } \\
\text { UNO }\end{array}$ & $\begin{array}{l}\text { As } \\
\text { microcontroller } \\
\text { and run the } \\
\text { programming } \\
\text { code. }\end{array}$ & \\
\hline 2. & $\begin{array}{c}\text { Light } \\
\text { Dependent } \\
\text { Resistor }\end{array}$ & $\begin{array}{l}\text { Detect the } \\
\text { darkness of } \\
\text { surrounding. }\end{array}$ & \\
\hline 3. & $\begin{array}{l}\text { Infrared } \\
\text { Sensor }\end{array}$ & $\begin{array}{l}\text { Detect the } \\
\text { presence of } \\
\text { object. }\end{array}$ & \\
\hline 4. & Battery & $\begin{array}{l}\text { Support the } \\
\text { voltage supply } \\
\text { to the Arduino. }\end{array}$ & \\
\hline 5. & LED & $\begin{array}{l}\text { LED treated as } \\
\text { street light. }\end{array}$ & \\
\hline
\end{tabular}

Figure 5 shows the circuit diagram of the proposed project. Referring on Table 1, each name of main component has been listed and marking by numbering as shown in Figure 5. Component 1 and 2 are IR 
sensor. Each IR sensor has theree connection pin which is VCC, GND and OUT. 5V voltage from the Arduino is connected to the breadboard. VCC pin from IR sensor 1 is connected to the connection of $5 \mathrm{~V}$ as well as IR sensor. Ground pin from the Arduino has been set to the breadboard and connect with GND at both IR sensor. LDR is connected to analog pin arduino which is pin A0 for sent data when data detect darkness and transmit the output. In second breadboard, it shows the connection of NPN transistor, zener diode and LED. This prototype used $12 \mathrm{~V}$ of LED so that the different level of intensity can be seen clearly. Hence, a connection between NPN transistor, zener diode and $1600 \Omega$ is needed when using high voltage LED. 9V battery is added to support voltage from the Arduino so that the whole system can be run. Table 2 shows the classes of speed that have been proposed in this project.

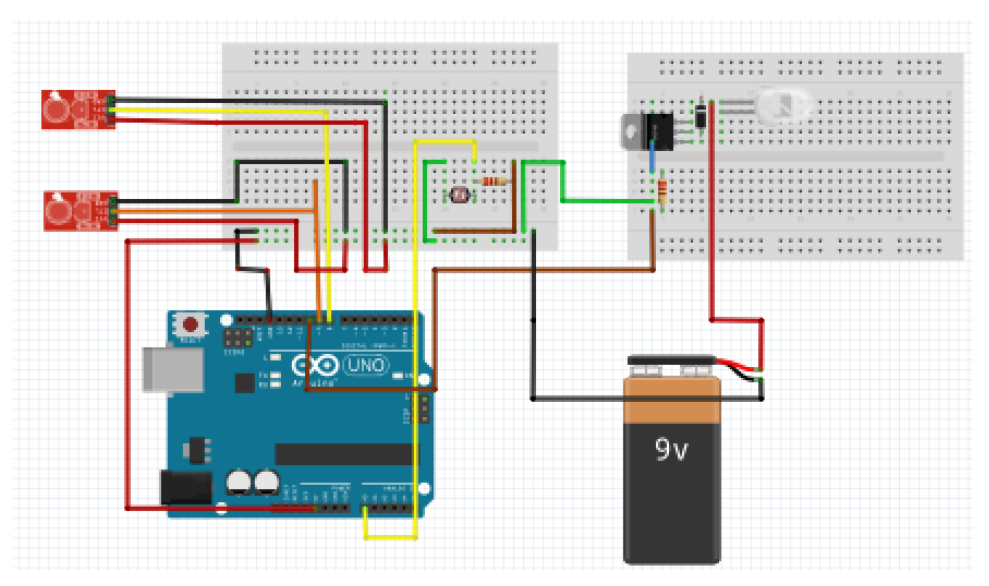

Figure 5. The circuit diagram to detect speed motion sensor [11]

Table 2. Classes of speed and their intensity [11]

\begin{tabular}{ccc}
\hline Condition & SPEED $(\mathrm{km} / \mathrm{h})$ & Intensity $(\%)$ \\
\hline Low & $0-5$ & 30 \\
Medium & $<15$ & 70 \\
High & $>15$ & 100 \\
\hline
\end{tabular}

\subsection{System flowchart}

Figure 6 shows the flowchart of speed detection system. The speed detection system starts with the initialization. System initialization means that all the variables must be initialized to zero. Then, Light Sensor (LDR) will detect the intensity of the light [12]. If the intensity of the light is low, then the next step is to use IR sensor to detect the object speed. When slow moving object is detected for example the speed is less than $5 \mathrm{~km} / \mathrm{h}$ which is normal speed of human walking [5], the level of intensity will increase by $30 \%$. In contrast, when the speed is more than $5 \mathrm{~km} / \mathrm{h}$ but less than $15 \mathrm{~km} / \mathrm{h}$ is detected, the speed is considered medium mode which it is a normal speed of cyclist, the light intensity will increase to $70 \%$. Finally, the light intensity will be at its full brightness (100\%) [4] when speed of more than $15 \mathrm{~km} / \mathrm{h}$ is detected [10].

\subsection{Design of prototype}

This proposed smart street light system uses a smallscale model as a prototype. The unit used in this paper is in centimeter. Table 3 show the ratios between the actual distance and the ratio unit used in this proposed system. While Figure 7 use the distance in meters unit whereas Figure 8 in centimeters as ratio in this prototype. Figure 8 shows an example of a pedestrian passed by the street light during night. Besides pedestrian, other objects like a cyclist and car that have a different speed of motion was also being detected by the proposed smart street light. Different light intensity is produced for different object. The higher the object's speed, the greater the level of intensity [12-13]. 


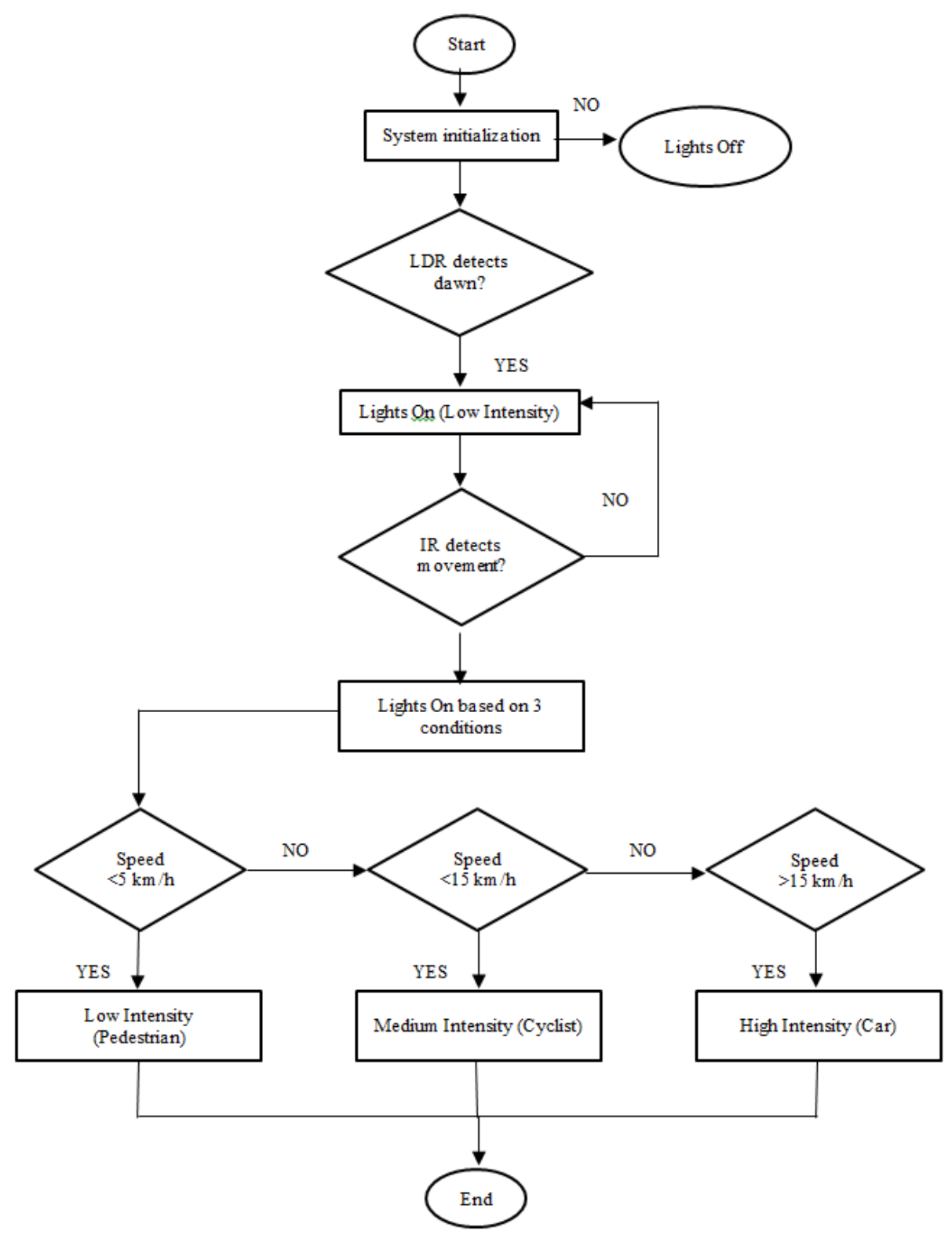

Figure 6. Flowchart to detect speed motion sensor [11]

Table 3. Suggestion ratio in real distance

\begin{tabular}{ccc}
\hline Measurement & Sensor 1 to sensor 2 & Sensor 2 to lamp pot \\
\hline Prototype distance $(\mathrm{cm})$ & 6 & 5 \\
Real distance $($ meter $)$ & 12 & 10 \\
\hline
\end{tabular}

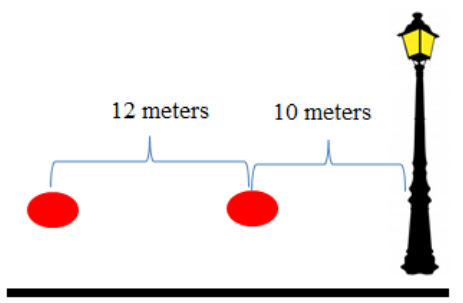

Figure 7. The dimension of real unit (meters)

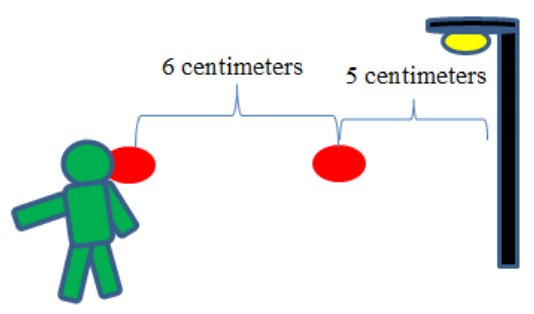

Figure 8. Dimension of the system proposed (cm)-Pedestrian detected 


\section{RESULTS AND ANALYSIS}

In this section, it is explained the results of research and at the same time is given the comprehensive discussion. Results can be presented in figures, graphs, tables and others that make the reader understand easily [10-11]. The discussion can be made in several sub-chapters.

\subsection{Effect of LDR and IR sensor on light intensity}

The main concern in this project is to reduce power consumption used by street lights by controlling the light intensity. This can be implemented in street light system by using sensor to detect the speed of movement. This proposed system is able to control the intensity of light as mentioned previously. LDR is used to detect darkness of surrounding while IR is used to detect the speed of the object. Figure 9 is the design of the prototype which consist of LDR and IR sensor as labelled in this figure. The final result of the light intensity that are successfully obtained in this project is shown in Figure 10. The light intensity level can be seen in different modes. Picture $\mathrm{A}$ is the condition of light when LDR detects darkness but with no movement. Picture B shows the $30 \%$ intensity of light such as a pedestrian is detected. While in picture $\mathrm{C}$ is the $70 \%$ intensity of light when speed of cyclist is detected and lastly picture D is the $100 \%$ level of light intensity when a car is detected.

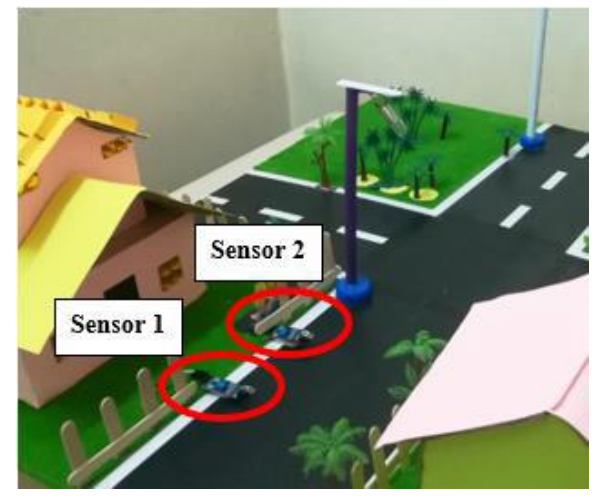

Figure 9. Design of prototype

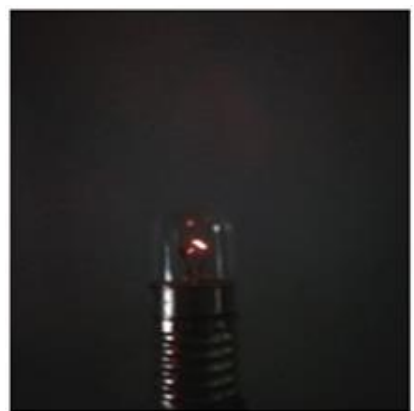

(a)

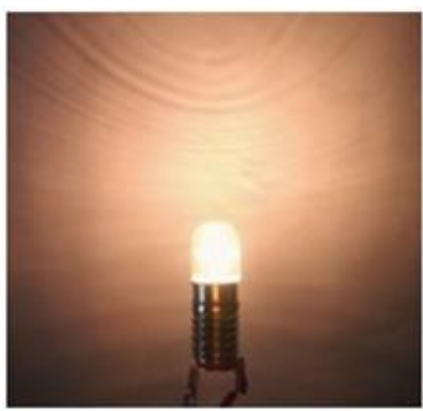

(c)

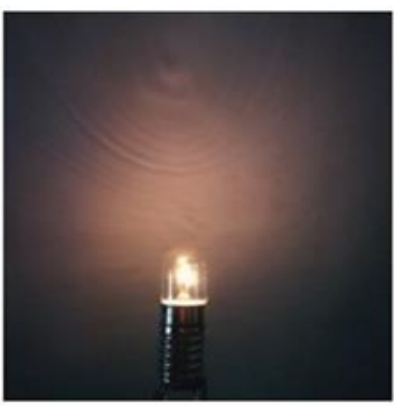

(b)

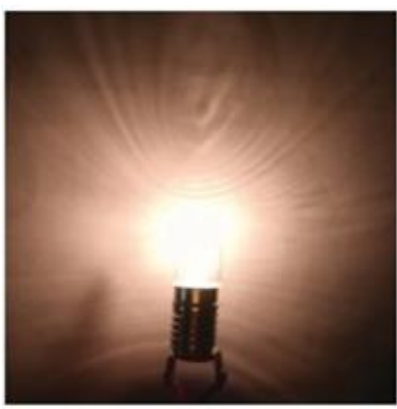

(d)

Figure 10. Intensity of LED light according to the speed of object movement, (a) Night mode, (b) Low mode, (c) Medium mode, (d) Fast mode 


\subsection{Effect of LED on power consumption}

In order to reduce the power consumption, this paper proposed to use LED lamp with $9 \mathrm{~W}$ of power. LED street lamps power is about $36 \mathrm{~W}$ or more. Since this project used $9 \mathrm{~W}$ LED power, therefore the energy consumption will be 9 Watt-hour. The electricity is measure in kilowatt-hour, hence it is $0.009 \mathrm{kWh}$. This calculation of power energy consumption by street light are estimated for a month (30 days). Therefore, the full intensity of LED for a month will be $0.27 \mathrm{kWh}$. The intensity value [13-14] and the calculated energy consumption and estimated saving is tabulated in Table 4.

Table 4. Hour wise power consumption [11]

\begin{tabular}{ccccc}
\hline Time duration & Intensity $(\%)$ & $\begin{array}{c}\text { Theoretical energy } \\
\text { consumption }(\mathrm{kWh})\end{array}$ & $\begin{array}{c}\text { Energy Consumption at } \\
100 \% \text { intensity }(\mathrm{kWh})\end{array}$ & $\begin{array}{c}\text { Estimated energy } \\
\text { Saving }(\mathrm{kWh})\end{array}$ \\
\hline $7 \mathrm{pm}-8 \mathrm{pm}$ & 100 & 0.27 & 0.27 & 0 \\
$8 \mathrm{pm}-9 \mathrm{pm}$ & 100 & 0.27 & 0.27 & 0 \\
9pm-10pm & 100 & 0.27 & 0.27 & 0 \\
$10 \mathrm{pm}-1 \mathrm{pm}$ & 80 & 0.216 & 0.27 & 0.054 \\
$11 \mathrm{pm}-12 \mathrm{am}$ & 70 & 0.189 & 0.27 & 0.081 \\
$12 \mathrm{am}-1 \mathrm{am}$ & 60 & 0.162 & 0.27 & 0.108 \\
$1 \mathrm{am}-2 \mathrm{am}$ & 50 & 0.135 & 0.27 & 0.135 \\
$2 \mathrm{am}-3 \mathrm{am}$ & 40 & 0.108 & 0.27 & 0.162 \\
3am-4am & 10 & 0.027 & 0.27 & 0.243 \\
$4 \mathrm{am}-5 \mathrm{am}$ & 15 & 0.0405 & 0.27 & 0.2295 \\
$5 \mathrm{am}-6 \mathrm{am}$ & 15 & 0.0405 & 0.27 & 0.2295 \\
$6 \mathrm{am}-7 \mathrm{am}$ & 50 & 0.135 & 0.27 & 0.135 \\
& Total & & 3.24 & 1.3767 \\
\hline
\end{tabular}

Estimated energy saving $=\frac{\text { Estimated energy saving }}{\text { Ebergy consumption full brightness }} \times 100 \%$

Estimated energy saving $=\frac{1.3767}{3.24} \times 100 \%$

Estimated Energy Saving=42.45\%

\subsection{Case study}

This part of the paper shares the case study where this project is based on the up closed situation in the International Islamic University of Malaysia (IIUM). IIUM consists of 8 main administrative building and 10 blocks of students' accommodation called Mahallah. Observation has been done around Mahallah Asiah and 15 lamp posts has been observed. From the observation, all 15 lamps are active from $7 \mathrm{pm}$ to $7 \mathrm{am}$ on 29 March 2018 with the same light intensity through out the night as shown in Figure 11.
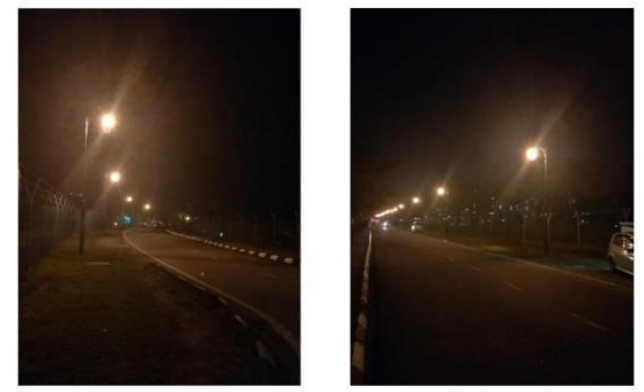

Figure 11. Active lamp posts at Mahallah Asiah on 29 March 2018

By referring to the data collected in Figure 12, the number of road users are decreasing through out at night on 29 March 2018. From the observation, the highest road users in Mahallah Asiah are pedestrians. From 7.00 AM until 11.00 PM the number of pedestrians around 70\% but stating 11.00 PM the number of pedestrians is drop until 2.00 AM. Up 2.00 AM, there is no pedestrian. While the number of cyclists are the smallest number among IIUM students. About 12\% students do the cyclists activity from 7.00 PM until 10.00 $\mathrm{PM}$ and the value is decrease until 12.00 AM. For the number of cars in this area, starting at 7.00 PM about $38 \%$ cars are counted use the streets. Obviously can be seen that at 2.00 AM until 6.00 AM, the road is empty 
with no road users. But the street light is kept light up with high intensity such huge waste of energy consumption. Therefore, it cannot be denied that the system of street light today is inefficient where huge waste of power consumption often occurs around us especially during the middle of the night.

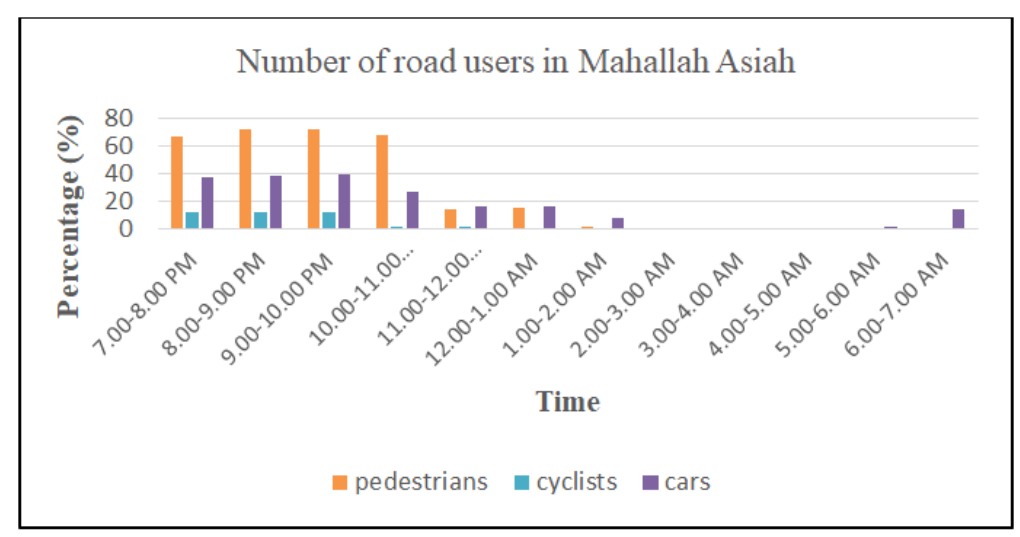

Figure 12. The number of road users in Mahallah Asiah on 29 March 2018

Based on the Figure 13, it shows the result of the observation to obtain the information about when is the time light should be active when people need it. This observation is observed within a month on 23 October 2017 until 22 November 2017 around IIUM campus. 23 over 30 days shows the sky gets dark early at 4.00 PM. This data shows the importance of a system that can detect the darkness of surrounding and turn on even before the set time at $7 \mathrm{PM}$.

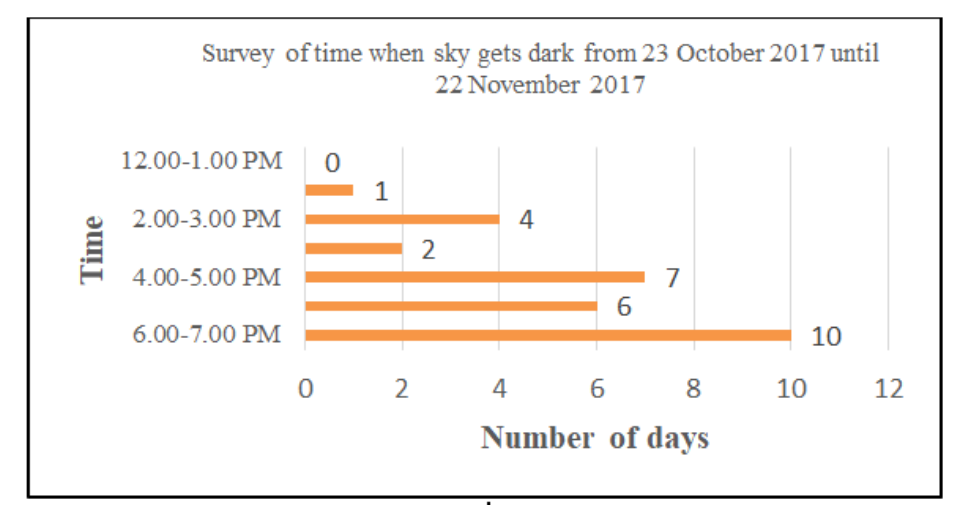

Figure 13. The graph of time gets dark in IIUM from 23 October 2017 until 22 November 2017

\section{CONCLUSION}

The goal of this project was to control the intensity of the street lights between $7.00 \mathrm{pm}$ until 7.00 am. This project is really important to be implemented because it can reduce the huge waste of power consumption by conventional street lights [14]. Therefore, this project has been done to calculate the power saving can be achieved using this sytem. The system detects the speed movement on the road and increase the intensity of the lights when there is movement and reduce the intensity after the movement has passed [15]. The objective of this paper has been achieved as the system proves that power electricity can be saved up to $40 \%$ to $45 \%$ per month.

\section{ACKNOWLEDGEMENTS}

This work was partially supported by Ministry of Higher Education Malaysia (Kementerian Pendidikan Tinggi) under Fundamental Research Grant Scheme (FRGS) number FRGS17-038-0604. 


\section{REFERENCES}

[1] H. Kopackova and P. Libalova, "Smart city concept as socio-technical system," 2017 International Conference on Information and Digital Technologies (IDT), Zilina, 2017, pp. 198-205.

[2] N. Khatavkar, A. A. Naik and B. Kadam, "Energy efficient street light controller for smart cities," 2017 International conference on Microelectronic Devices, Circuits and Systems (ICMDCS), Vellore, 2017, pp. 1-6.

[3] F. Report, "Smart LED Street Lighting," pp. 1-36.

[4] H. A. Attia, A. Omar and M. Takruri, "Design of decentralized street LED light dimming system," 2016 5th International Conference on Electronic Devices, Systems and Applications (ICEDSA), Ras Al Khaimah, 2016, pp. 1-4.

[5] D. R. Khade, N. V. Gajane, S. N. Gawade and R. A. Metri, "Intensity controller of LED street lights," 2017 International Conference on Circuit ,Power and Computing Technologies (ICCPCT), Kollam, 2017, pp. 1-4.

[6] N. Yoshiura, Y. Fujii and N. Ohta, "Smart street light system looking like usual street lights based on sensor networks," 2013 13th International Symposium on Communications and Information Technologies (ISCIT), Surat Thani, 2013, pp. 633-637.

[7] V. K. Bhangdiya, "Low power consumption of LED street light based on smart control system," 2016 International Conference on Global Trends in Signal Processing, Information Computing and Communication (ICGTSPICC), Jalgaon, 2016, pp. 619-622.

[8] Siti Hajar Yusoff, Nur Shahida Midi, Sheroz Khan, Majdee Tohtayong, "Predictive control of AC/AC matrix converter, " International Journal of Power Electronics and Drive System, vol. 8, no. 4, pp. 1932-1942, 2017.

[9] M. Kuusik, T. Varjas and A. Rosin, "Case study of smart city lighting system with motion detector and remote control," 2016 IEEE International Energy Conference (ENERGYCON), Leuven, 2016, pp. 1-5.

[10] A. Gupta and S. Gupta, "Design of Automatic Intensity Varying Smart Street Lighting System," IOP Conference Series: Materials Science and Engineering, vol. 225, pp. 012126, 2017.

[11] A. Abdullah, S. H. Yusoff, S. A. Zaini, N. S. Midi, and S. Y. Mohamad, "Smart Street Light Using Intensity Controller," 2018 7th Int. Conf. Comput. Commun. Eng., pp. 1-5, 2018.

[12] Tamizharasi, A., Selvathai, J.J., Kavi Priya, A., Maarlin, R., Harinetha, M., "Energy aware heuristic approach for cluster head selection in wireless sensor networks," Bulletin of Electrical Engineering and Informatics, vol. 6, no. 1. pp. 70-75, 2017

[13] A. Toubal, B. Bengherbia, M. Ouldzmirli and M. Maazouz, "Energy efficient street lighting control system using wireless sensor networks," 2016 8th International Conference on Modelling, Identification and Control (ICMIC), Algiers, 2016, pp. 919-924.

[14] N. Khatavkar, A. A. Naik and B. Kadam, "Energy efficient street light controller for smart cities," 2017 International conference on Microelectronic Devices, Circuits and Systems (ICMDCS), Vellore, 2017, pp. 1-6.

[15] Pinto, M. F., Mendonça, T. R. F., Duque, C. A., \& Braga, H. A. C. (2016). Street Lighting System for Power Quality Monitoring and Energy-Efficient Illumination Control, 34-39.

\section{BIOGRAPHIES OF AUTHORS}

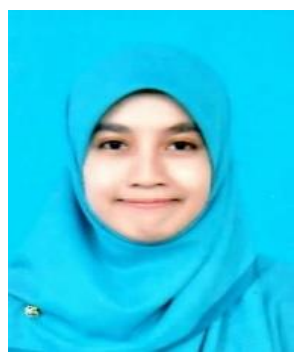

Aziera Abdullah received the B.E degree in electrical and electronic engineering majoring communication from International Islamic University Malaysia (IIUM), Malaysia in 2018, where she is currently working toward the master's degree. Her current research interest is in designing and analyzing wireless charging for electric vehicles.

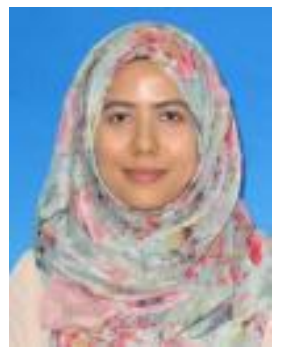

Siti Hajar Yusoff received a MEng. Degree (1st Class Hons) in Electrical Engineering from the University of Nottingham, UK and a Ph.D. degree in Electrical and Electronic Engineering from the University of Nottingham, U.K., in 2009 in 2014, respectively. She has been appointed as an Assistant Professor in the Department of Electrical and Computer Engineering, Faculty of Engineering, International Islamic University Malaysia (IIUM). Her current research interests include IoT (Internet of Things), Smart cities, non-linear control, renewable energy, wireless dynamic charging in electric cars. 


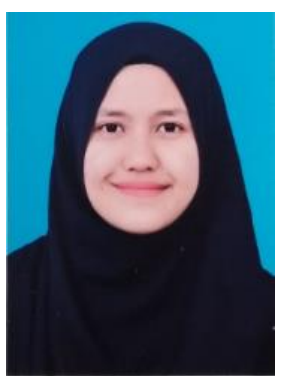

Syasya Azra Zaini received the B.E degree in electrical and electronic engineering majoring communication from International Islamic University Malaysia (IIUM), Malaysia in 2018, where she is currently working toward the master's degree. Her research interest is designing and analyzing inductive pad coupler in dynamic wireless power transfer for electric vehicle.

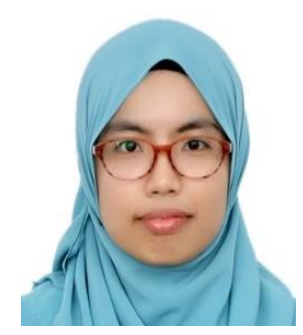

Nur Shahida Midi obtained her Doctor of Engineering (Science and Technology) from Tokai University, Japan. She is currently an Assistant Professor at Department of Electrical and Computer Engineering, Faculty of Engineering, International Islamic University of Malaysia (IIUM). Her research interests are high voltage engineering, electrical power engineering, Internet of Things (IoT) and waste management.

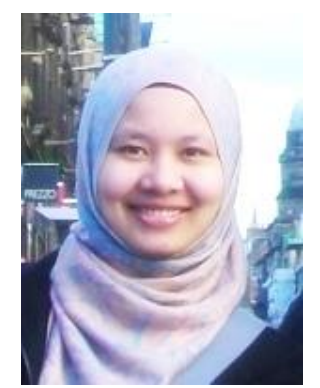

Sarah Yasmin Mohamad received a MEng. degree in Communication and Computer Engineering from the Universiti Kebangsaan Malaysia (UKM) and a Ph.D. degree in Electrical and Electronic Engineering from the Queen's University Belfast, Belfast, U.K., in 2011 in 2015, respectively. She has been appointed as an Assistant Professor in the Department of Electrical and Computer Engineering, Faculty of Engineering, International Islamic University Malaysia (IIUM). Her current research interests include antennas and wave propagation and wireless communication systems. 